Saudi Journal of Oral and Dental Research

Abbreviated Key Title: Saudi J Oral Dent Res

ISSN 2518-1300 (Print) |ISSN 2518-1297 (Online)

Scholars Middle East Publishers, Dubai, United Arab Emirates

Journal homepage: https://saudijournals.com/sjodr

\title{
Connotation of Otological Symptom in Tempro Mandibular Joint Disorder and Vise-Versa (Clinical Comparative Original Study)
}

\author{
Dr. Waleed MB Yahya Alsabea ${ }^{1}$, Dr. Rawaa Younus Al-Rawee ${ }^{2 *}$
}

${ }^{1}$ Specialist ENT, M.B.Ch.B, Iraqi Board Medical Specialist, ENT Technical Affairs Department, Nineveh Health Directorate, Iraq

${ }^{2}$ BDS., M.Sc OS., MOMS MFDSRCPS Glasgow. Ph.D. MaxFacs, Consultant, Department Of Oral and Maxillofacial Surgery, Al-Salam Teaching Hospital, Mosul, Iraq

DOI: $10.36348 /$ sjodr.2020.v05i11.002

| Received: 01.11.2020 | Accepted: 08.11.2020 | Published: 13.11.2020

*Corresponding author: Rawaa Younus Al-Rawee

Abstract

Many articles have highlighted the association between otological symptoms and TMJD. Anatomic, neurologic and emotional relationships considered the causative factors of symptom association. According to multiple published literatures otalgia can be common sign for TMJD subjects with tenderness and pain on mandibular condyle. Aims of study: The temporomandibular joint disorder may be accompanied by a series of otological symptoms such as otalgia, investigators aims here in this clinical study multiple points such as analyzing the prevalence of different symptoms of TMJD, else more to estimate the importance of cooperation between two different specialties these are maxillofacial and ENT specialties. To verify the frequency of otologic signs and symptoms with TMJ disorder and vice versa; specifying to which limit the therapeutic intervention on the articular pathology may influence the manifestations. Furthermore; authors targeting to detect the influence of proper diagnosis and selection of proper treatment plane. Emphasize the different correlation between the two specialties. Material and Method: One hundred participants are sharing in this research divided equally in to dual specialties origin, fifty patients attain private clinic of the maxillofacial surgeon and fifty participants attain private ear nose throat clinic. All of these patients are share to have temporomandibular joint disorders (TMJDS) and otological symptom (OS) but they attain different specialty. Result: One hundred patients shared in TMJDS and OS analyzed according to different age groups as well as gender difference. Descriptive analyses for cases in both specialties are cleared the highest incidences are highlighted. Thirty-one to forty forming the highest age group in both specialties $(38 \%, 30 \%)$ consequently for maxillofacial and ENT patients. Most of the mutants are females (74\%) equally for both branches. Comparison between patients attain maxillofacial clinic and patients attain ENT clinic are analyzed according to age and gender in respect to symptoms, investigations, site involved, question answer. Discussion: The management of patients with TMD is a challenge, and an approach that includes dentists and oto-rhinolaryngologists is necessary to rule out, for example, otological diseases. It is imperative to understand the need for interdisciplinary management between the doctor and the dental specialist in craniofacial pain. Also try for a conservative vision in the treatment of muscular tensions of these masticatory and auditory muscles. Specialists in a single discipline cannot always individually resolve the symptoms present in a patient, without the invaluable support of multidisciplinary management. Each specialty contributes in its specific knowledge to the differential diagnosis process that guides a correct treatment plan.

Keywords: Pain, Temporomandibular Joint Disorders, Tinnitus, Clicking, Otitis.

Copyright () 2020 The Author(s): This is an open-access article distributed under the terms of the Creative Commons Attribution 4.0 International License (CC BY-NC 4.0) which permits unrestricted use, distribution, and reproduction in any medium for non-commercial use provided the original author and source are credited.

\section{INTRODUCTION}

Temporomandibular joint dysfunctions being considered the third stomatological disease in regard to inhabitant illness owing to its chronicity and widespread prevalence, E. Ferendiuk stated that "the disorders occur in more than $10 \%$ of population" [1].

Epidemiological data confirm that painful TMJ disease is increasing (to about $40 \%$ ) while the age of patients are dropped; furthermore female are affected more than male [2]. In this circumstances; such problem can disturb individuals' capability causing restriction to achieve every day functions at home and work; this can make discussing and solving patients' compline are priorities [1].

There is no doubt that the functional relevance between stomatognathic system and the acousticvestibular apparatus are widely discussed in many 
points such as anatomical, physiological and symptomatical relation. Temporomandibular disorder (TMJD) is an idiom reflects different clinical problems involve mastication muscles and temporomandibular joint with its associated structures.

Etiology of TMJD is varied can be ranged from mild stress and emotional problems, muscle hyper or hypoactivity to more advanced causes as occlusion disturbances, degenerative disorder, traumatic causes and harmful habits that generate persistent [3].

Pain, clicking or crackling sounds in the TMJ, in addition limitation of mouth opening are utmost clinical symptoms of TMJD. Pain can spread to different regions of the head, including the pre-auricular and auricular regions [4].

Many articles have highlighted the association between otological symptoms and TMJD [5-7]. Anatomic, neurologic and emotional relationships considered the causative factors of symptom association.

According to multiple published literatures otalgia can be common sign for TMJD subjects with tenderness and pain on mandibular condyle palpation $[8,9]$. In addition, tinnitus, vertigo and ear fullness show high prevalence association moreover $[10,11]$.

\section{AIMS OF STUDY}

The TMJD may be accompanied by a series of otological symptoms such as otalgia, investigators aim from this clinical study multiple points such as analyzing the prevalence of different symptoms of TMJD, else more to estimate the importance of cooperation between two different specialties these are maxillofacial and ENT specialties. To verify the occurrence of otologic signs and symptoms with TMJ disorder and vice versa; specifying to which limit the therapeutic intervention on the articular pathology may influence the manifestations. Furthermore; authors targeting to detect the influence of proper diagnosis and selection of proper treatment plane. Emphasize the different correlation between the two specialties.

\section{MATERIAL AND METHOD}

One hundred participants are sharing in this research divided equally in both specialties origin, fifty patients attain private clinic of the maxillofacial surgeon and fifty participants attain private ear nose throat clinic. All of these patients are share to have temporomandibular joint disorders (TMJDS) and otological symptom (OS) but they attain different specialty.

\section{Inclusion Criteria}

- $\quad$ Patient with age from 14-70 y

- No sex predilection.
- Patients have Tempro Mandibular Joint Disorder

- Patients agree to share in research with predictable follow-up.

\section{Exclusion Criteria}

- Patients don't have Tempro Mandibular Joint Disorder

- Systemically unfit patients

- Drugs allergies that affect postoperative healing.

- Patients rejected to share.

- Poor follow-up cases.

This study is approved ethically by the Authorized Ethical Scientific Committee in Nineveh Health Directorate for work and publishing with the license number $20 / 100$. Study conducted in the period from (1/1/2019 - 30/12/2019). Informed consent, patient agreement for participations and for publishing is signed.

All clinical records routinely used for patients treated at these 2 private clinics for a six- month's period were initially selected, for a total 197 patients record. Ninety seven patients are excluded either no complete data or no fit the eligibility criteria. Final sample was 100 records

Demographical patient information are recorded include identity details, history both medical and dental, physical and clinical examinations, which involve temporomandibular joint area and the ear region too. Muscles of mastication and muscles of the head included in examination, functional tests of the temporomandibular joint and occlusion details also recorded.

Clinical sign and symptom are recorded as appropriate to reach definite diagnosis in full details in accordance to branches. For maxillofacial surgeon; these are pain type, intensity, site extension, causes, elevating factors, reducing factors, period and number of pain attacks with previous treatment underwent. Tenderness as well as clicking in the site is documented. On the contrary; pain, hearing loss and tinnitus are chronicled by the ENT surgeon. Line of treatment provided and Follow up for both branches are estimated more over.

The specific shared question in both branches is "What is the first symptom making you seek treatment: ear or joint".

The data analyzed were gender (male and female), age (up to 20 years old, between 21 and 30, between 31 and 40, between 41 and 50, and 51 or older). Related symptoms such as dizziness, ear 
fullness, and imbalance recorded but not included in the parameters.

Microsoft Excel used to record data which analyzed by Statistical Package for Social Sciences (SPSS) software program IBM version 20. Primarily informative analyses were done

The correlation between age and the symptoms in different branches are estimated. Comparisons between age and symptoms in different branch were performed also. Same analysis carried out for gender as well. Analysis of the question's answer also valued. Moreover the correlation between otological symptoms and temporomandibular disorder are analyzed. Temporomandibular site involved analysis (Right, Left or Both). Estimation of difference in line of treatment and percentage of referral between the two specialties is analyzed. The significance level was $5 \%$.

\section{RESULT}

\section{Descriptive Analyses}

One hundred patients shared in TMJDS and OS analyzed according to different age groups as well as gender difference. Descriptive analyses for cases in both specialties are cleared in Table-1. The highest incidences are highlighted. Thirty-one to forty forming the highest age group in both specialties $(38 \%, 30 \%)$ consequently for maxillofacial and ENT patients. Most of the mutants are females (74\%) equally for both branches.

Comparison between patients attain maxillofacial clinic and patients attain ENT clinic are analyzed according to age and gender in respect to symptoms, investigations, site involved, question answer and follow up as will be explained consequently.

\section{Symptoms Comparison}

Table 2 and 3 show the symptoms comparison in regards to age groups in both specialties were pain tenderness as well as clicking show significant difference between maxillofacial and ENT patients (0.034, 0.48, 0.049 consequently). Age group (31-40 years) shows the highest percent $38 \%$ in maxillofacial cases. On the contrary pain, hearing loss and tinnitus don't show significant difference in addition the age groups (21-30 and 31-40 years) show equal high percentage $(26 \%)$.

Gender express no significant difference in both branches whether TMJD symptoms or otological one (Figures 1 and 2).

\section{Investigations Comparison}

Thirty patients are performing radiographical assessment added to clinical examinations for maxillofacial patients while zero patients investigated by radiograph in ENT patients, no significant difference illustrated (0.218) (Table-4).

\section{Site Involvement Comparison}

Both TMJ involvement display a significant difference between maxillofacial and ENT patients (0.012), Thirty one patients screening bilateral joint symptoms from these $38 \%$ in age group (21-30 and 3140 years). Age groups (21-30 and 31-40) accountings about more than half of ENT patients collectively (28\%) were left TMJ involved (Table-5).

\section{Question Answer}

All participants are asked one question about which symptom makes him seek treatment whether joint pain or ear pain? Maxillofacial patients exhibit a significant result 0.004 , thirty nine patients answer clearly that pain in TMJ area make them pursues maxillofacial clinic, eleven patients are referred from ENTs to consultate maxillofacial surgeon. All patients attain ENT' clinic responds that ear pain is the priorities (Table-6).

\section{Follow up Comparison}

Two weeks follow up don't illustrate significance differences quit the opposite four weeks follow up display significance result (0.019). Thirty seven maxillofacial patients were responding to treatment in the first two weeks in contrast to eight ENT patients (Table-7).

\section{Gender Relations}

Equivalent comparisons are also done in regards to gender with symptoms, investigation, site involved, question answer and follow up periods. No significant differences are exhibited in all in spite of that gender manifest significant relation in conformity to TMJ pain $(0.001,0.001)$, tenderness $(0.001,0.004)$, otological pain $(0.001,0.001)$ for both specialties and tinnitus (0.005) added to ENT's patients.

Concerning site involvement in maxillofacial patients; both site (right and left) also right side only esteems significant relation with gender $(0.007,0.020)$ on opposing left side and both sides express significance relation in ENT's patients $(0.033,0.035)$. All these are shown in table eight and Figure-3. 
Table-1: Descriptive Analysis of Cases in Both Specialties

\begin{tabular}{|c|c|c|c|c|c|}
\hline \multirow{2}{*}{\multicolumn{2}{|c|}{ Description }} & \multicolumn{2}{|c|}{ Maxillofacial Clinic (MFC) } & \multicolumn{2}{|c|}{ ENT Clinic (ENTC) } \\
\hline & & N. & $\%$ & N. & $\%$ \\
\hline \multirow{5}{*}{ Age Group } & Less than $20 \mathrm{y}$ & 4 & $8 \%$ & 10 & $20 \%$ \\
\hline & $21-30 \mathrm{y}$ & 16 & $32 \%$ & 14 & $28 \%$ \\
\hline & $31-40 y$ & 19 & $38 \%$ & 15 & $30 \%$ \\
\hline & $41-50 \mathrm{y}$ & 2 & $4 \%$ & 8 & $16 \%$ \\
\hline & Over $51 \mathrm{y}$ & 9 & $18 \%$ & 3 & $6 \%$ \\
\hline \multirow[t]{2}{*}{ Gender } & Male & 13 & $26 \%$ & 13 & $26 \%$ \\
\hline & Female & 37 & $74 \%$ & 37 & $74 \%$ \\
\hline \multirow[t]{6}{*}{ Symptom } & TMJ Pain & 50 & $100 \%$ & 36 & $72 \%$ \\
\hline & Tenderness & 50 & $100 \%$ & 43 & $86 \%$ \\
\hline & Clicking & 50 & $100 \%$ & 12 & $24 \%$ \\
\hline & Ear Pain & 16 & $32 \%$ & 44 & $\mathbf{8 8 \%}$ \\
\hline & Hearing Loss & 0 & $0 \%$ & 15 & $30 \%$ \\
\hline & Tinnitus & 7 & $14 \%$ & 32 & $64 \%$ \\
\hline \multirow[t]{2}{*}{ Investigation } & Yes & 30 & $60 \%$ & 0 & $0 \%$ \\
\hline & No & 20 & $40 \%$ & 0 & $0 \%$ \\
\hline \multirow[t]{3}{*}{ Site Involved } & Right side & 9 & $18 \%$ & 17 & $34 \%$ \\
\hline & Left Side & 10 & $20 \%$ & 22 & $44 \%$ \\
\hline & Both Sides & 31 & $62 \%$ & 11 & $22 \%$ \\
\hline \multirow[t]{2}{*}{ Question Answers } & TMJ & 38 & $76 \%$ & 0 & $0 \%$ \\
\hline & Ear & 11 & $22 \%$ & 50 & $100 \%$ \\
\hline
\end{tabular}

Table-2: TMJD Symptom Compares in Both Specialties in Relation to Age

\begin{tabular}{|c|c|c|c|c|c|c|c|c|c|c|c|c|}
\hline \multirow[t]{3}{*}{ Age Group } & \multicolumn{4}{|c|}{ Pain } & \multicolumn{4}{|c|}{ Tenderness } & \multicolumn{4}{|c|}{ Clicking } \\
\hline & \multicolumn{2}{|c|}{ MFC } & \multicolumn{2}{|c|}{ ENTC } & \multicolumn{2}{|c|}{ MFC } & \multicolumn{2}{|c|}{ ENTC } & \multicolumn{2}{|c|}{ MFC } & \multicolumn{2}{|c|}{ ENTC } \\
\hline & $\mathbf{N}$. & $\%$ & N. & $\%$ & N. & $\%$ & N. & $\%$ & N. & $\%$ & N. & $\%$ \\
\hline Less than -20 & 4 & $8 \%$ & 8 & $16 \%$ & 4 & $8 \%$ & 8 & $16 \%$ & 4 & $8 \%$ & 0 & $0 \%$ \\
\hline $21-30$ & 16 & $32 \%$ & 12 & $24 \%$ & 16 & $32 \%$ & 10 & $20 \%$ & 16 & $32 \%$ & 2 & $4 \%$ \\
\hline $31-40$ & 19 & $38 \%$ & 10 & $20 \%$ & 19 & $38 \%$ & 14 & $28 \%$ & 19 & $38 \%$ & 3 & $6 \%$ \\
\hline $41-50$ & 2 & $4 \%$ & 5 & $10 \%$ & 2 & $4 \%$ & 8 & $16 \%$ & 2 & $4 \%$ & 4 & $8 \%$ \\
\hline Over -51 & 9 & $18 \%$ & 1 & $2 \%$ & 9 & $18 \%$ & 3 & $6 \%$ & 9 & $18 \%$ & 3 & $6 \%$ \\
\hline Sig. & 0.03 & & & & & & & & & & & \\
\hline
\end{tabular}

Table-3: Otological Symptom Compares in Both Specialties in relation to Age

\begin{tabular}{|c|c|c|c|c|c|c|c|c|c|c|c|c|}
\hline \multirow[t]{3}{*}{ Age Group } & \multicolumn{4}{|c|}{ Pain } & \multicolumn{4}{|c|}{ Hearing loss } & \multicolumn{4}{|c|}{ Tinnitus } \\
\hline & \multicolumn{2}{|c|}{ MFC } & \multicolumn{2}{|c|}{ ENTC } & \multicolumn{2}{|c|}{ MFC } & \multicolumn{2}{|c|}{ ENTC } & \multicolumn{2}{|c|}{ MFC } & \multicolumn{2}{|c|}{ ENTC } \\
\hline & N. & $\%$ & N. & $\%$ & N. & $\%$ & N. & $\%$ & N. & $\%$ & N. & $\%$ \\
\hline Less than -20 & 2 & $4 \%$ & 9 & $18 \%$ & 0 & $0 \%$ & 6 & $12 \%$ & 0 & $0 \%$ & 4 & $8 \%$ \\
\hline 21-30 & 4 & $8 \%$ & 13 & $26 \%$ & 0 & $0 \%$ & 2 & $4 \%$ & 1 & $2 \%$ & 10 & $20 \%$ \\
\hline $31-40$ & 6 & $12 \%$ & 13 & $26 \%$ & 0 & $0 \%$ & 1 & $2 \%$ & 4 & $8 \%$ & 10 & $20 \%$ \\
\hline 41-50 & 1 & $2 \%$ & 6 & $12 \%$ & 0 & $0 \%$ & 2 & $4 \%$ & 0 & $0 \%$ & 6 & $12 \%$ \\
\hline Over $\mathbf{- 5 1}$ & 2 & $4 \%$ & 3 & $6 \%$ & 0 & $0 \%$ & 3 & $6 \%$ & 2 & $4 \%$ & 2 & $4 \%$ \\
\hline Sig. & \multicolumn{4}{|c|}{0.78} & \multicolumn{4}{|c|}{0.150} & \multicolumn{4}{|c|}{0.503} \\
\hline
\end{tabular}

Table-4: Investigation Compares in Both Specialties in Relation to Age and Gender

\begin{tabular}{|l|l|l|l|l|l|}
\hline \multirow{4}{*}{ Age Group } & \multirow{2}{*}{ Description } & \multicolumn{3}{|l|}{ Investigation } \\
\cline { 3 - 6 } & & \multicolumn{2}{|l|}{ MFC } & \multicolumn{2}{l|}{ ENTC } \\
\cline { 3 - 6 } & & N. & \% & N. & \% \\
\cline { 2 - 6 } & Less than -20 & 3 & $6 \%$ & 0 & $0 \%$ \\
\cline { 2 - 6 } & $\mathbf{2 1 - 3 0}$ & 9 & $18 \%$ & 0 & $0 \%$ \\
\cline { 2 - 6 } & $\mathbf{3 1 - 4 0}$ & 11 & $22 \%$ & 0 & $0 \%$ \\
\cline { 2 - 6 } & $\mathbf{4 1 - 5 0}$ & 1 & $2 \%$ & 0 & $0 \%$ \\
\cline { 2 - 6 } & $\mathbf{5 1 - \text { Above }}$ & 6 & $12 \%$ & 0 & $0 \%$ \\
\hline Sig. & & 0.218 & \multicolumn{5}{|l|}{} \\
\hline Gender & Male & 4 & $8 \%$ & 0 & $0 \%$ \\
\cline { 2 - 6 } & Female & 26 & $52 \%$ & 0 & $0 \%$ \\
\hline Sig. & & 0.624 & \multicolumn{4}{|c}{} \\
\hline
\end{tabular}


Table-5: Site Involvement Compares in Both Specialties According to Age Groups

\begin{tabular}{|c|c|c|c|c|c|c|c|c|c|c|c|c|}
\hline \multirow[t]{3}{*}{ Age Groups } & \multicolumn{4}{|c|}{ Rt TMJ } & \multicolumn{4}{|c|}{ Lt TMJ } & \multicolumn{4}{|c|}{ В TMJ } \\
\hline & \multicolumn{2}{|c|}{ MFC } & \multicolumn{2}{|c|}{ ENTC } & \multicolumn{2}{|c|}{ MFC } & \multicolumn{2}{|c|}{ ENTC } & \multicolumn{2}{|c|}{ MFC } & \multicolumn{2}{|c|}{ ENTC } \\
\hline & N. & $\%$ & N. & $\%$ & N. & $\%$ & N. & $\%$ & N. & $\%$ & N. & $\%$ \\
\hline Less than -20 & 0 & $6 \%$ & 1 & $2 \%$ & 1 & $6 \%$ & 4 & $8 \%$ & 3 & $6 \%$ & 5 & $10 \%$ \\
\hline 21-30 & 4 & $18 \%$ & 7 & $14 \%$ & 3 & $18 \%$ & 6 & $12 \%$ & 9 & $18 \%$ & 1 & $2 \%$ \\
\hline $31-40$ & 4 & $8 \%$ & 5 & $10 \%$ & 5 & $10 \%$ & 8 & $16 \%$ & 10 & $20 \%$ & 2 & $4 \%$ \\
\hline 41-50 & 0 & $0 \%$ & 2 & $4 \%$ & 0 & $0 \%$ & 3 & $6 \%$ & 2 & $4 \%$ & 3 & $6 \%$ \\
\hline Over -51 & 1 & $2 \%$ & 2 & $4 \%$ & 1 & $2 \%$ & 1 & $2 \%$ & 7 & $14 \%$ & 0 & $0 \%$ \\
\hline Sig. & \multicolumn{4}{|c|}{0.989} & \multicolumn{4}{|c|}{0.318} & \multicolumn{4}{|c|}{$0.012 *$} \\
\hline
\end{tabular}

Table-6: Question Answer for Both Specialties in relation to Age and Gender

\begin{tabular}{|c|c|c|c|c|c|c|c|c|c|}
\hline \multirow[t]{9}{*}{ Age Group } & \multirow[t]{4}{*}{ Description } & \multicolumn{4}{|c|}{ Maxillofacial } & \multicolumn{4}{|c|}{ ENT } \\
\hline & & \multicolumn{4}{|c|}{ Question Answer } & \multicolumn{4}{|c|}{ Question Answer } \\
\hline & & \multicolumn{2}{|c|}{ Joint } & \multicolumn{2}{|c|}{ ear } & \multicolumn{2}{|c|}{ Joint } & \multicolumn{2}{|c|}{ ear } \\
\hline & & N. & $\%$ & $\mathbf{N}$. & $\%$ & N. & $\%$ & $\mathbf{N}$. & $\%$ \\
\hline & Less than -20 & 3 & $6 \%$ & 1 & $2 \%$ & 0 & $0 \%$ & 10 & $20 \%$ \\
\hline & $21-30$ & 12 & $24 \%$ & 4 & $8 \%$ & 0 & $0 \%$ & 14 & $28 \%$ \\
\hline & $31-40$ & 16 & $32 \%$ & 3 & $6 \%$ & 0 & $0 \%$ & 15 & $30 \%$ \\
\hline & 41-50 & 1 & $2 \%$ & 1 & $2 \%$ & 0 & $0 \%$ & 8 & $16 \%$ \\
\hline & $51-\mathrm{Al}$ & 7 & $14 \%$ & 2 & $4 \%$ & 0 & $0 \%$ & 3 & $6 \%$ \\
\hline Sig. & & \multicolumn{2}{|c|}{$0.004 *$} & \multicolumn{2}{|c|}{0.543} & \multicolumn{2}{|c|}{1.000} & \multicolumn{2}{|c|}{0.052} \\
\hline \multirow[t]{2}{*}{ Gender } & Male & 8 & $16 \%$ & 4 & $8 \%$ & 0 & $0 \%$ & 13 & $26 \%$ \\
\hline & Female & 30 & $60 \%$ & 7 & $14 \%$ & 0 & $0 \%$ & 37 & $74 \%$ \\
\hline Sig. & & \multicolumn{2}{|c|}{$0.000^{*}$} & \multicolumn{2}{|c|}{0.366} & \multicolumn{2}{|c|}{1.000} & \multicolumn{2}{|c|}{$0.001 *$} \\
\hline
\end{tabular}

Table 7: Follow up Comparison for Both Specialties in Relation to Age

\begin{tabular}{|l|l|l|l|l|l|l|l|l|}
\hline \multirow{3}{*}{ Age Groups } & \multicolumn{4}{|l|}{ 2weeks } & \multicolumn{2}{l|}{ 4 weeks } \\
\cline { 2 - 9 } & MFC & \multicolumn{1}{l|}{ ENTC } & \multicolumn{2}{l|}{ MFC } & \multicolumn{2}{l|}{ ENTC } \\
\cline { 2 - 9 } & N. & \% & N. & \% & N. & \% & N. & \% \\
\hline Less than -20 & 2 & $4 \%$ & 3 & $6 \%$ & 1 & $2 \%$ & 6 & $12 \%$ \\
\hline $\mathbf{2 1 - 3 0}$ & 14 & $28 \%$ & 2 & $4 \%$ & 11 & $22 \%$ & 10 & $20 \%$ \\
\hline $\mathbf{3 1 - 4 0}$ & 15 & $30 \%$ & 3 & $6 \%$ & 12 & $24 \%$ & 11 & $22 \%$ \\
\hline $\mathbf{4 1 - 5 0}$ & 1 & $2 \%$ & 0 & $0 \%$ & 0 & $0 \%$ & 7 & $14 \%$ \\
\hline Over -51 & 5 & $10 \%$ & 0 & $0 \%$ & 4 & $8 \%$ & 1 & $2 \%$ \\
\hline
\end{tabular}

Table-8: ENTC Symptom in Relation to Gender

\begin{tabular}{|c|c|c|c|c|c|c|c|c|c|c|c|c|}
\hline \multirow[t]{3}{*}{ Gender } & \multicolumn{6}{|c|}{ TMJ Symptom } & \multicolumn{6}{|c|}{ Otological Symptom } \\
\hline & \multicolumn{2}{|c|}{ Pain } & \multicolumn{2}{|c|}{ Tenderness } & \multicolumn{2}{|c|}{ Clicking } & \multicolumn{2}{|c|}{ Pain } & \multicolumn{2}{|c|}{ Hearing loss } & \multicolumn{2}{|c|}{ Tinnitus } \\
\hline & $\mathbf{N}$. & $\%$ & $\mathbf{N}$. & $\%$ & $\mathbf{N}$. & $\%$ & $\mathbf{N}$. & $\%$ & $\mathbf{N}$. & $\%$ & $\mathbf{N}$. & $\%$ \\
\hline $\mathbf{M}$ & 8 & $16 \%$ & 12 & $24 \%$ & 5 & $10 \%$ & 11 & $22 \%$ & 4 & $8 \%$ & 8 & $16 \%$ \\
\hline $\mathbf{F}$ & 28 & $56 \%$ & 31 & $62 \%$ & 7 & $14 \%$ & 33 & $66 \%$ & 11 & $22 \%$ & 24 & $48 \%$ \\
\hline Sig. & \multicolumn{2}{|c|}{$0.001 *$} & \multicolumn{2}{|c|}{$0.004 *$} & \multicolumn{2}{|c|}{0.564} & \multicolumn{2}{|c|}{$0.001 *$} & \multicolumn{2}{|c|}{0.071} & \multicolumn{2}{|c|}{$0.005 *$} \\
\hline
\end{tabular}

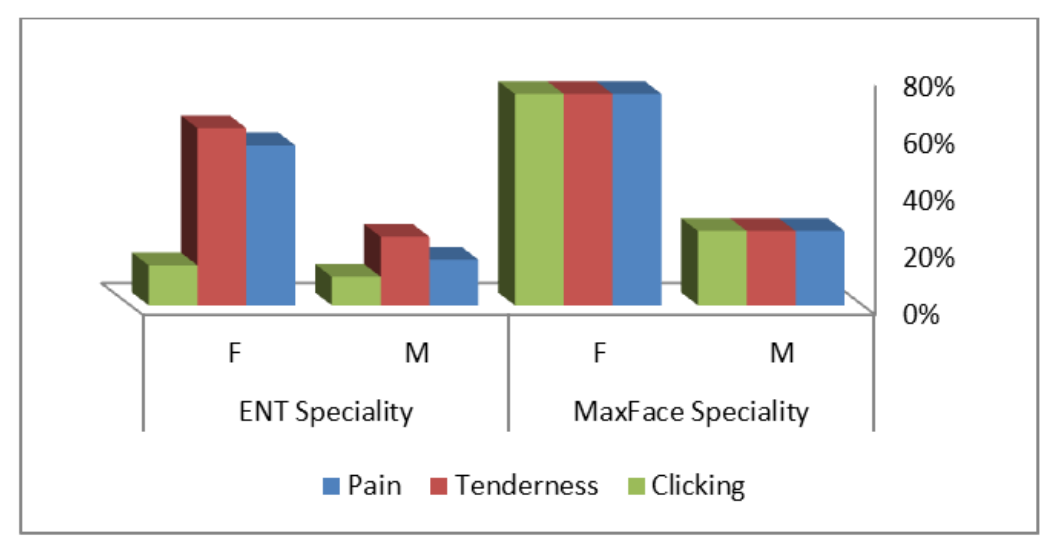

Fig-1: TMJD Symptom Compares in Both Specialties 


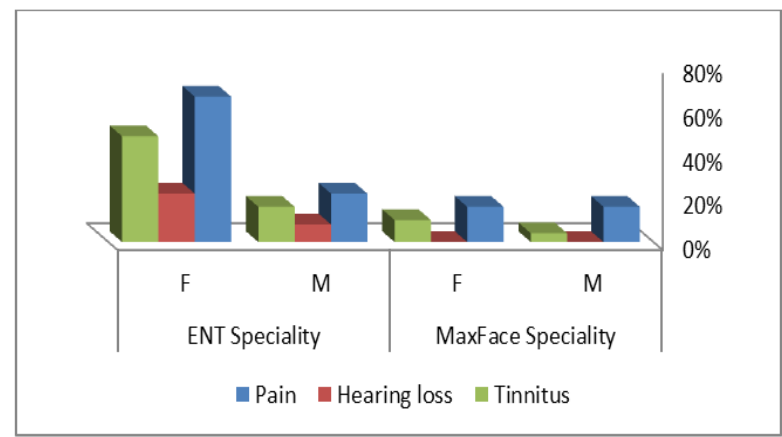

Fig-2: Otological Symptom Compares in Both Specialties

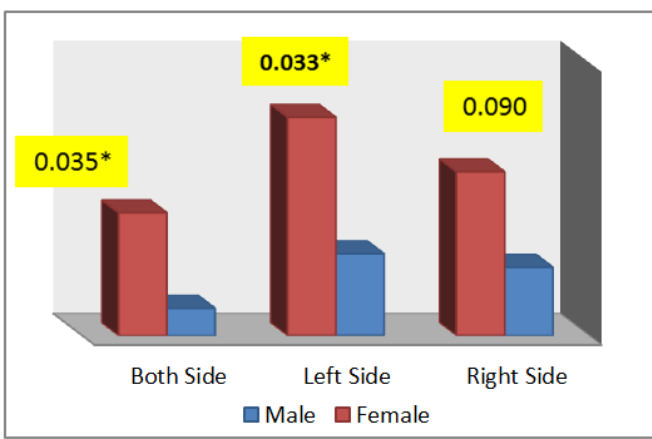

Fig-3: Site Involvement for ENT Specialties According to Gender

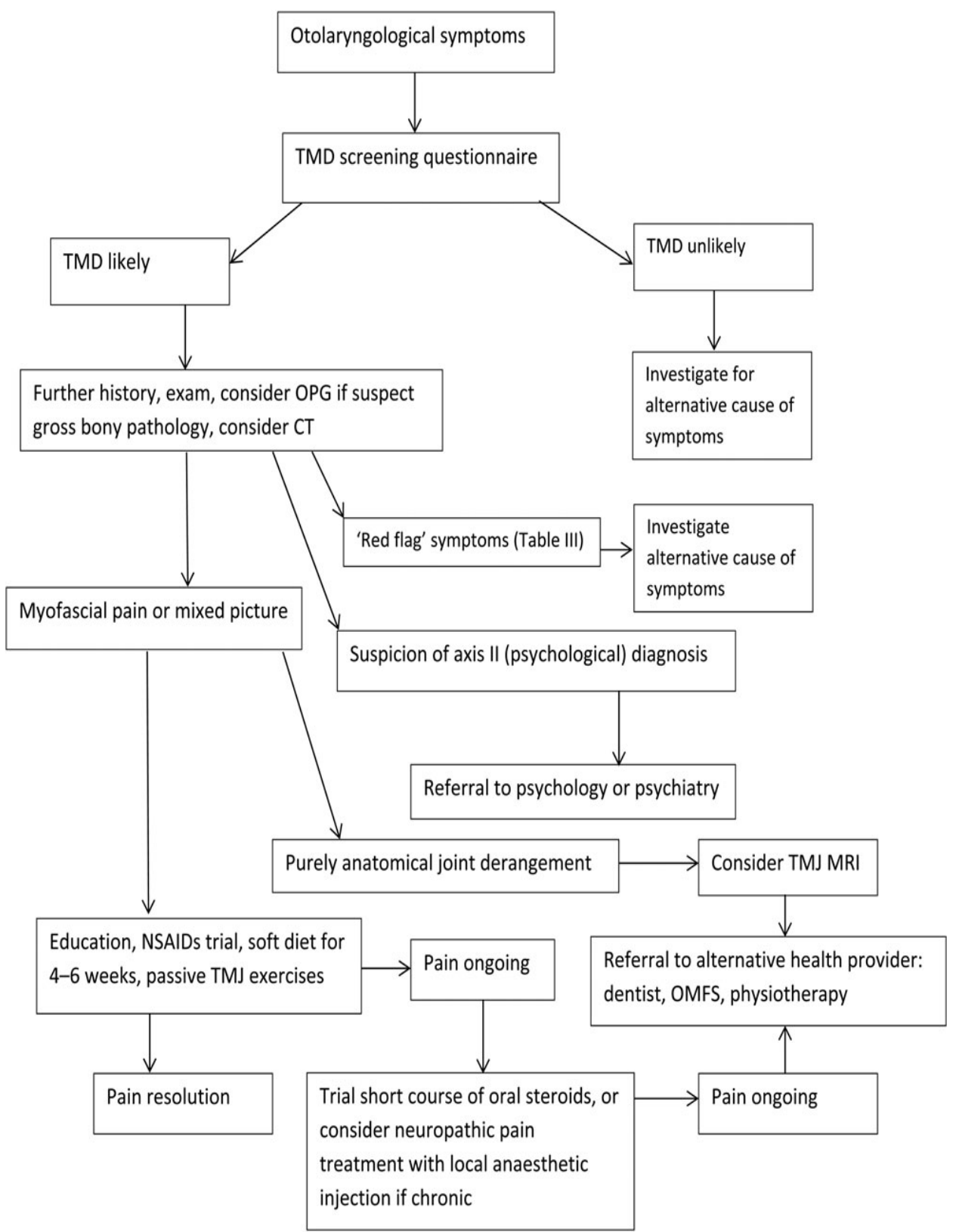

Fig-4: Proposed management pathway for suspected temporomandibular disorder by Stephan [32]

\section{DISCUSSION}

The academic and clinical knowledge of anatomy gathered for years represent an indisputable proof of the connection that exists between the both entities, but there is a continuing argument nowadays about the TMJ pathology extension that can generate otological symptoms. 
Temporomandibular joint disorder is common disorder display multiple symptoms and varied terminology are screened in the literature such as "painful myofascial syndrome" or "occlusal-articular algodysfunctional syndrome". In some instances, it can affect patients' capability even causing psychological disturbances as it can manifest symptom with teeth, muscle or joint which can extend affecting and influence the diminution of the manifestations of the acoustic-vestibular system [12].

About $60-70 \%$ of the general population has at least one sign of temporomandibular joint dysfunction (TMD), but only one out of four individuals is aware of these symptoms and reports them to a specialist [13]. Many etiological factors are coincident to cause TMJD; simply these are highlighted with details in a review article published by Chisnoiu 2015. Occlusion conflicts, psychology disorders as well as hormones disturbances can affect the disease occurrences. In some cases hereditary factors also have a role [14].

Pain is the most common symptom alarming the patients and encourages them to looking for treatment. Severity with extensions of pain are diverse, may radiate to the preauricular, nasal, orbital, occipital, mastoid, supraclavicular level. Gabriela Musat 2017 an ENT surgeon focuses on importance of TMJ pain differential diagnosis [12]. This is in the line with the result of this study as pain forming the highest symptom for both specialties.

Musat also conclude that TMJD predominantly unilateral beside the connotation of otic phenomena; on the contrary of the result of this study which show significance result in bilateral site involvement $(0.012 *)$ for maxillofacial patients. This can be related to different hypotheses as proposed by Ren and Isberg show a" significant correlation between the unilateral presence of tinnitus and the movement of the condyle from the TMJ" [13]; mechanical transmission forces basically are possibility for such tinnitus from the TMJ transmission to the middle ear, via the disco-malleolar ligament [15]. Likewise, auriculotemporal nerve irritation by condylar part of the joint can be another hypothesis explains unilateral pain of otic area [16].

Most common otic symptom associated with the TMJD is otalgia. Kasnisci et al., have demonstrated an incidence of otalgia of $66.7 \%$, Lam et al., of $32 \%$, while Tuz et al., of 57.2\% [17-19]. Fifty nine patients are complaining from otalgia collectively in both specialties forming more the half of all patients $59 \%$ are the result of this study agreed with the previous mentioned articles.

Hearing loss occur in 14 patients; six out of them are below 20 years of age in this study; Decker described cases series of hearing impairment manifest in patients with deep occlusion or posterior localization of the mandibular condyle in the glenoid fossa [16]. Furthermore, Goodfriend 1933, noted the link between the incidence of tinnitus and the stomatognathic system dysfunction, argument also approached by Costen in 1934. Other author considers there is an increase in tinnitus intensity with up to $75 \%$ during voluntary movements of the temporo mandibular joint [12].

Le Resche L. climax the age prevalence with TMJD; he describe it as" it follow an inverted U curve" [20]. Age incidences are controversial. Age from 45- 64 years olds express the peak prevalence [21, 22] while prevalence peaked in women of child bearing ages (20 40 year-olds) in older studies [23]. Despite the relatively high prevalence of TMD in the elderly population, there are no current review articles that focus on this specific age group [24].

Conventionally, TMD thought to trouble women. This also approved in recent prospective study discuss orofacial pain conclude same evidence that only the chronic form of TMD disease predominantly afflicted women. Moreover various cross sectional studies confirm that increased prevalence of TMD found in women $[25,26]$. This is equivalent to this study, as females can affect more with psychological factors and hormonal factors.

Bagis 2012; publish a retrospective study on 243 consecutive patients; giving similar evidences that females are affected more than males (171/72) [27].

Dentist or maxillofacial surgeons when dealing with TMJD patients usually try to look for the etiology of such conditions before passing to management as clinical examinations only can be vague and indistinct; radiographs are highly important as an investigation protocol before. ENTs usually can discover source of patients complain by use of otoscope device to examine the ear for such reason radiographs might have no role. Nicholas L. 2020 publish a ENT book on otoscope examination emphasize that most of clinician perform this type of examination for assessment of different ENT disease as the external auditory canal (EAC), tympanic membrane (TM), and the middle ear [28].

Daniel et al., 2018 declare that not all patients need radiographical assessment, many cases can be treated by clinical examinations solely; which is the most important step in the diagnosis of TMJ pathology, "special imaging techniques are needed due to the complex anatomy and pathology" [29]. Epstein et al., [30] consider the "clinical findings of greater relevance than panoramic images for patients with TMD". Nevertheless, some authors have suggested panoramic radiography as a good imaging modality for TMJ visualization [31]. Joint function interpretation can be estimated through imaging TMJ which can be accomplished by comparing the condyle in the closed and opened mouth position so individual selection 
criteria will make clinician properly decide which patients would need special imaging techniques. In this study; ENT ' surgeon depends on clinical examinations only to manage the patients. Thirty maxillofacial patients are treated depends on clinical and radiographical assessment.

There is no conflict by choosing patients for the private clinic to treat their problems this settled through analyzing patients' answers about the first symptom making them seek treatment: ear or joint. Otalgia pursue patients going to ENT clinics whereas 39 patients attain maxillofacial clinic complain from TMJ pain, rest of participants (11) are attain the same clinic although of presence of ear pain not TMJ pain. This can be attributed to connotation of the symptoms and their severities disturb the patients' decisions.

One month medical treatment is enough periods to cure simple to moderate TMJDS; in severe cases other advanced management' protocols can be used. Stephan et al., 2017 [32]; publish in his systematic review article a special proposed management pathway for suspected temporomandibular disorder with otological symptoms (Figure 4) as well as V. Santosh 2020; focus on special management considerations cited for both otolaryngologists and dentists concluding that "since the symptoms of TMD are overlaid with otological symptoms, such patients may commonly visit otolaryngologists. A comprehensive evaluation as suggested in this article from the literature would be a good tool for the otolaryngologists as well as dentists to follow for better management of TMD patients" [33].

Recognizing and diagnosing the TMJ disorder patients with otalgia need intimate teamwork support between dental specialist in craniofacial pain and ENT's. Otorhinolaryngologist should "confirm the absence of any significant or detectable auditory, genetic, drug-related, or trauma-related causes of otalgia" [34]. Then, referral to experienced dentist in treating TMJD for suspected TMJ disorder cases.

This study requires further studies to detect the influence of proper diagnosis and selection of proper treatment in cooperation with TMJ centers.

The management of patients with TMD is a challenge, and should approach through multidisciplinary team work to rule out, for example, otological diseases. Clinical evaluation is essential and should explore signs and symptoms, assessment of ergonomic posture, and visual and physical examination of the extraoral and intraoral regions (including palpation of the head and neck muscles) and the TMJ [35].

It is imperative to understand the need for interdisciplinary management between the doctor and the dental specialist in craniofacial pain. Also try for a conservative vision in the treatment of muscular tensions of these masticatory and auditory muscles. Specialists in a single discipline cannot always individually resolve the symptoms present in a patient, without the invaluable support of multidisciplinary management. Each specialty contributes in its specific knowledge to the differential diagnosis process that guides a correct treatment plan. Clinical success therefore depends on the ability of each specialist to analyze different aspects of the same problem [36].

\section{CONCLUSION}

TMJD is a common performance can be seen in general practice settings. Primary care setting for TMJD includes assessment clinically and radiographically if need ending with diagnosis of TMJD. Conservative approaches in most instances are the best management way. In the majority of instances a trial of conservative therapy should be offered prior to referral to specialist care.

Patients' quality life can be affected through TMJD symptoms specifically pain, psychological discomfort. Identifying etiological factors as fast as possible should approach through multidisciplinary team work are highly crucial to provide appropriate treatments plan to improve and eliminate the debilitating symptoms of TMD.

\section{Author Contributions}

Author is contributed to acquisition, statistical analysis and interpretation of data, drafted the manuscript and critically revised the manuscript for important intellectual content. Author gave final approval and agrees to be accountable for all aspects of the work in ensuring that questions relating to the accuracy or integrity of any part of the work are appropriately investigated and resolved.

Conflict of Interest: The authors report no conflicts of interest related to this review.

\section{Funding Statement: No Funding Sources}

Acknowledgements: Great thanks for the institutional research committee in Nineveh Health Directorate.

\section{REFERENCES}

1. Ferendiuk, E., Zajdel, K., \& Pihut, M. (2014). Incidence of otolaryngological symptoms in patients with temporomandibular joint dysfunctions. BioMed Research International, 2014.

2. Piorkowska-Skrabucha, B., Czelej-Piszcz, E., Litko, M., \& Kleinrok, J. (2008). Subjective Symptoms in Mandibular Dysfunctions - a review of the literature. Implantoprotetyka, 9(2):46-50. 
3. Totta, T., Santiago, G., Gonçales, E. S., Saes, S. D. O., \& Berretin-Felix, G. (2013). Auditory characteristics of individuals with temporomandibular dysfunctions and dentofacial deformities. Dental press journal of orthodontics, 18(5), 70-77.

4. Magalhães, B. G., de Melo Freitas, J. L., da Silva Barbosa, A. C., Gueiros, M. C. S. N., Gomes, S. G. F., Rosenblatt, A., \& Júnior, A. D. F. C. (2018). Temporomandibular disorder: otologic implications and its relationship to sleep bruxism. Brazilian journal of otorhinolaryngology, 84(5), 614-619.

5. Morais, A. A., \& Gil, D. (2012). Tinnitus in individuals without hearing loss and its relationship with temporomandibular dysfunction. Brazilian journal of otorhinolaryngology, 78(2), 59-65.

6. Hilgenberg, P. B., Saldanha, A. D. D., Cunha, C. O., Rubo, J. H., \& Conti, P. C. R. (2012). Temporomandibular disorders, otologic symptoms and depression levels in tinnitus patients. Journal of oral rehabilitation, 39(4), 239-244.

7. Calderon, P. D. S., Hilgenberg, P. B., Rossetti, L. M. N., Laurenti, J. V. E. H., \& Conti, P. C. R. (2012). Influence of tinnitus on pain severity and quality of life in patients with temporomandibular disorders. Journal of Applied Oral Science, 20(2), 170-173.

8. Keersmaekers, K. D. D. S., De Boever, J. A., \& Van Den Berghe, L. (1996). Otalgia in patients with temporomandibular joint disorders. The Journal of prosthetic dentistry, 75(1), 72-76.

9. dos Reis, A. C., Hotta, T. H., Ferreira-Jerônymo, R. R., de Felício, C. M., \& Ribeiro, R. F. (2000). Ear symptomatology and occlusal factors: a clinical report. Journal of Prosthetic Dentistry, 83(1), 21-24.

10. Kuttila, S., Kuttila, M., Le Bell, Y., Alanen, P., \& Jouko, S. (1999). Aural symptoms and signs of temporomandibular disorder in association with treatment need and visits to a physician. The Laryngoscope, 109(10), 1669-1673.

11. Rodrigues, A. C. Y., Berretin, G., Jorge, J. C., \& Genaro, K. F. (1998). Caracterizaçäo das alteraçöes miofuncinais orais e auditivas em indivíduos com disfunçäo craniomandibular. Prófono, 10(1), 51-5.

12. Musat, G., Neaga, L. F., \& Enache, R. (2017). Otologic symptomatology associated with the temporomandibular joint disorder. Romanian Journal of Rhinology, 7(28), 215-224.

13. Chisnoiu, A. M., Picos, A. M., Popa, S., Chisnoiu, P. D., Lascu, L., Picos, A., \& Chisnoiu, R. (2015). Factors involved in the etiology of temporomandibular disorders-a literature review. Clujul medical, 88(4), 473-478.

14. Ren, Y. F., \& Isberg, A. (1995). Tinnitus in patients with temporomandibular joint internal derangement. CRANIO®, 13(2), 75-80.
15. Ramírez Aristeguieta, L. M., Sandoval Ortiz, G. P., \& Ballesteros, L. E. (2005). Theories on otic symptoms in temporomandibular disorders: past and present. International journal of morphology, 23(2), 141-156.

16. Decker, J. C. (1925). XXXIX. Traumatic Deafness as a Result of Retrusion of the Condyles of the Mandible (Preliminary Report). Annals of Otology, Rhinology \& Laryngology, 34(2), 519-527.

17. Kisnisci, R., Onder, E., \& Tuz, H. (1999). Prevalence of otologic complaints in temporomandibular disorder patients. International Journal of Oral and Maxillofacial Surgery, 28, 101-102.

18. Lam, D. K., Lawrence, H. P., \& Tenenbaum, H. C. (2001). Aural symptoms in temporomandibular disorder patients attending a craniofacial pain unit. Journal of orofacial pain, 15(2):146-157.

19. Tuz, H. H., Onder, E. M., \& Kisnisci, R. S. (2003). Prevalence of otologic complaints in patients with temporomandibular disorder. American Journal of Orthodontics and Dentofacial Orthopedics, 123(6), 620-623.

20. LeResche, L. (1997). Epidemiology of temporomandibular disorders: implications for the investigation of etiologic factors. Critical Reviews in Oral Biology \& Medicine, 8(3), 291-305.

21. Maixner, W., Fillingim, R. B., Williams, D. A., Smith, S. B., \& Slade, G. D. (2016). Overlapping chronic pain conditions: implications for diagnosis and classification. The Journal of Pain, 17(9), T93-T107.

22. LORA, V. R. M. M., Canales, G. D. L. T., Goncalves, L. M., Meloto, C. B., \& BARBOSA, C. M. R. (2016). Prevalence of temporomandibular disorders in postmenopausal women and relationship with pain and HRT. Brazilian oral research, 30(1):e100.

23. Warren, M. P., \& Fried, J. L. (2001). Temporomandibular disorders and hormones in women. Cells Tissues Organs, 169(3), 187-192.

24. Yadav, S., Yang, Y., Dutra, E. H., Robinson, J. L., \& Wadhwa, S. (2018). Temporomandibular Joint Disorders in the Elderly and Aging Population. $J$ Am Geriatr Soc. 66(6):1213-1217.

25. Slade, G. D., Bair, E., Greenspan, J. D., Dubner, R., Fillingim, R. B., Diatchenko, L., ... \& Ohrbach, R. (2013). Signs and symptoms of first-onset TMD and sociodemographic predictors of its development: the OPPERA prospective cohort study. The Journal of Pain, 14(12), T20-T32.

26. Manfredini, D., Guarda-Nardini, L., Winocur, E., Piccotti, F., Ahlberg, J., \& Lobbezoo, F. (2011). Research diagnostic criteria for temporomandibular disorders: a systematic review of axis I epidemiologic findings. Oral Surgery, Oral Medicine, Oral Pathology, Oral Radiology, and Endodontology, 112(4), 453-462.

27. Bagis, B., Ayaz, E. A., Turgut, S., Durkan, R., \& Özcan, M. (2012). Gender difference in prevalence 
of signs and symptoms of temporomandibular joint disorders: a retrospective study on 243 consecutive patients. International journal of medical sciences, 9(7), 539-544.

28. Nicholas, L. (2020). Mankowski; Blake S. Raggio. Otoscope Exam. 2020. Jan. Last Update: March 30, 2020. Treasure Island (FL): StatPearls Publishing; Bookshelf ID: NBK553163 PMID: 31985956 Copyright (C) 2020, StatPearls Publishing LLC. (http://creativecommons .org/licenses/by/4.0/),

29. Talmaceanu, D., Lenghel, L. M., Bolog, N., Hedesiu, M., Buduru, S., Rotar, H., ... \& Baciut, G. (2018). Imaging modalities for temporomandibular joint disorders: an update. Clujul Medical, 91(3), 280.

30. Epstein, J. B., Caldwell, J., \& Black, G. (2001). The utility of panoramic imaging of the temporomandibular joint in patients with temporomandibular disorders. Oral Surgery, Oral Medicine, Oral Pathology, Oral Radiology, and Endodontology, 92(2), 236-239.

31. Brooks, S. L., Westesson, P. L., Eriksson, L., Hansson, L. G., \& Barsotti, J. B. (1992). Prevalence of osseous changes in the temporomandibular joint of asymptomatic persons without internal derangement. Oral surgery, oral medicine, oral pathology, 73(1), 118-122.

32. Stepan, L., Shaw, C. L., \& Oue, S. (2017). Temporomandibular disorder in otolaryngology: systematic review. The Journal of Laryngology \& Otology, 131(S1), S50-S56.

33. Santosh, V., Hinduja, S., Manoj, R., \& Waghmare, M. (2020). Overlaid temporomandibular joint disorders and otology symptoms-A diagnostic approach and management considerations for otolaryngologists and dentists. Eastern Journal of Medical Sciences.

34. Buraa, M. F., \& Alazzawi, H. S. (2013). The relationship among otic clinical findings and temporomandibular joint disorders population. Iraqi Academic Scientific Journal, 12(4), 546-550.

35. Ramirez, L. M., Ballesteros, L. E., \& Sandoval, G. P. (2007). Otological symptoms among patients with temporomandibular joint disorders. Revista medica de Chile, 135(12), 1582-1590.

36. Maciel, L. F. O., Landim, F. S., \& Vasconcelos, B. C. (2018). Otological findings and other symptoms related to temporomandibular disorders in young people. British Journal of Oral and Maxillofacial Surgery, 56(8), 739-743. 